\title{
Ralstonia solanacearum Induction Causes Biochemical and Oxidative Stress Isozyme Variations in Mangroves without Wilt
}

\author{
Sasidharan Sreedevi ${ }^{1,2}$, Sreedharan Sajith ${ }^{1}$, Kulangara Nanu Remani ${ }^{2}$, Sailas Benjamin ${ }^{{ }^{*}}$ \\ ${ }^{1}$ Enzyme Technology Laboratory, Biotechnology Division, Department of Botany, University of Calicut, Calicut, India; ${ }^{2}$ Environ- \\ mental Studies Division, Centre for Water Resources Development and Management (CWRDM), Calicut, India. \\ Email: ${ }^{*}$ sailasben@yahoo.co.in, ${ }^{*}$ benjamin@uoc.ac.in
}

Received August $1^{\text {st }}, 2013$; revised September $1^{\text {st }}, 2013$; accepted September $20^{\text {th }}, 2013$

Copyright (C) 2013 Sasidharan Sreedevi et al. This is an open access article distributed under the Creative Commons Attribution License, which permits unrestricted use, distribution, and reproduction in any medium, provided the original work is properly cited.

\begin{abstract}
We evaluated the effects of Ralstonia solanacearum (Rs) induced biotic stress in three mangroves, viz., Avicennia officinalis, Derris trifoliata and Excoecaria agallocha. These plants were grown in pots as well as hydroponic systems with sufficient controls, and about $8 \times 10^{4}$ colony forming units of $R s$ suspension was injected into the healthy test plants (saplings). The plants were subjected to biochemical and isozyme analyses. Upon induction of $R s$ stress, highly significant $(p<0.01)$ biochemical changes $(\%)$ were noticed in respect to controls: carbohydrate content was generally high (24 - 36) in all plants; hydroponic mangroves showed higher starch content, mangroves under hydroponic system showed increased reducing sugars (29 - 46), almost all mangroves showed increased protein content; phenolics showed a swing of decrease or increase between plants grown in pot and hydroponic systems; and all plants in general showed higher proline content. Regarding oxidative stress isozymes (OSE) and superoxide dismutase (EC1.15.1.1), mangroves showed 1 or 2 additional isozymes with comparable relative mobility; similarly 1 or 2 additional peroxidase (EC1.11.1.7) isozymes were found in mangroves grown under hydroponic system. Briefly, $R s$ induced biotic stress did not cause any wilt symptom in all the 3 mangroves tested, but their normal biochemical and OSE patterns, especially of those grown as hydroponics were elicited to significantly higher levels.
\end{abstract}

Keywords: R. solanacearum; Avicennia officinalis L.; Derris trifoliata Lour.; Excoecaria agallocha L.

\section{Introduction}

Ralstonia solanacearum $(R s)$ is a Gram negative, soilborne pathogen causing bacterial wilt in many agronomically important cultivars [1,2]. It invades xylem vessels and causes vascular dysfunction by their extensive colonization, thereby causing wilt [3]. Upon wound or cut, Rs oozes out as a streaming thread along with its mucus secretion. Plant stress relates to any change in growth condition(s) that disrupts metabolic homeostasis and requires an adjustment of metabolic pathways in a process that is usually referred to as acclimation [4]; in other words, any unfavourable condition or substance that affects or blocks a plant's metabolism, growth, or development [5]. Compared to abiotic stress, scientific information on biotic stress due to pathogenic attack is very much scanty. Biotic stressors or stress factors are

${ }^{*}$ Corresponding author. those concerned with the mechanism of interaction between populations. For instance, biotic stressors such as viruses, fungi, bacteria, weeds, insects and other pests and pathogens are a major constraint to agricultural productivity from fields to markets in the world. Persistently sub-optimal environmental conditions constitute stress [6].

Invasion of plant pathogens results in an oxidative burst exemplified by the overproduction of superoxide, hydrogen peroxide and hydroxyl radicals (these are the reactive oxygen species, ROS), which are effectively scavenged by oxidative stress enzyme (OSE) like superoxide dismutase (SOD; EC 1.15.1.1), a wide variety of peroxidases (POX; EC 1.11.1.11), and catalase (CAT; EC 1.11.1.6). The generation of these stress tolerant proteins is determined by specific enzyme assay methods and relative mobility $(\mathrm{Rm})$ of these protein bands upon electrophoresis [7]. Differential changes in isoforms of some 
antioxidant enzymes in the mangrove, Bruguiera parviflora were analyzed by quantifying the intensity of bands formed after electrophoresis [8]. For the study of stress physiology in plants, both pot [9] and hydroponic [8] systems of cultivation have widely been used.

Most of the stress physiology studies have been focused on the changes in morphological, biochemical and molecular profiles of plants during abiotic stress. Effect of biotic stress on the stress physiology is mainly confined to a few cultivable plants. Even though mangroves are widely studied for various abiotic stressors, the effect of biotic stress (especially pathogenic) is not addressed in them and also less documented even in cultivars. Thus, we designed this study to evaluate the changes in the biochemical profiles and OSE isozyme patterns, after infected with $R s$, in three mangroves. Accordingly, the specific objectives are to: 1) frame a suitable experimental design, 2) cultivate 3 mangroves in pot and hydroponic systems with sufficient controls, 3) transfer $R s$ isolate artificially in to these plants, 4) analyse the plants for biochemical changes, 5) analyse the changes of SOD, POX and CAT isoymes in these plants.

\section{Materials and Methods}

\subsection{Microbial Isolate Used}

$R$. solanacearum $(R s)$ we isolated from infected ginger was used to impart biotic stress on the selected mangroves used as test plants [10].

\subsection{Collection of Test Plants}

Three mangroves (Avicennia officinalis L., Derris trifoliata Lour. and Excoecaria agallocha L.), were used in this study. The mangroves which have just germinated were collected from the marshy wetland situated along the Canoli canal, near Kottuli in Kozhikode, Kerala, India $\left(11^{\circ} 15^{\prime} 30 " \mathrm{~N}\right.$; $\left.75^{\circ} 48^{\prime} 8^{\prime \prime E}\right)$ during South-West monsoon, and were transported to the lab.

\subsection{Method of Cultivation}

A. officinalis, D. trifoliata and E. agallocha were planted in two environments: in well nourished pots and saplings in hydroponic condition. Each group (in pot and as hydroponics) of plants was grown in sufficient numbers (5 each) for control and treatment (injected with Ralstonia solanacearum isolate).

\subsubsection{Cultivation in Pot}

A mixture of garden soil, sand and farmyard manure (1:1:1) was used to cultivate the test plants in pot. Plants were raised in a green house with a night time temperature between $20^{\circ} \mathrm{C}$ and $25^{\circ} \mathrm{C}$ and a day time temperature beween $29^{\circ} \mathrm{C}$ and $34^{\circ} \mathrm{C}$ for one month, which were further transferred to open air. Vigor of the test plants was maintained by frequent watering. The treated plants were kept away from the control to prevent spreading of $R s$ infection [10].

\subsubsection{Cultivation in Hydroponic System}

One month old healthy saplings (in green house), were transferred to hydroponic system. Shive and Robbins medium [11] was used for the cultivation of plants in hydroponic system. It contained $(\mathrm{g} / \mathrm{L}): 3.4 \mathrm{NaNO}_{3} ; 1.665$ $\mathrm{CaCl}_{2} ; 2.14 \mathrm{KH}_{2} \mathrm{PO}_{4} ; 5.14 \mathrm{MgSO}_{4}$ and trace elements like $0.00275 \quad \mathrm{FeSO}_{4} \cdot 7 \mathrm{H}_{2} \mathrm{O} ; 0.00285 \quad \mathrm{H}_{3} \mathrm{BO}_{3} ; 0.00285$ $\mathrm{MnSO}_{4}$, and $0.00285 \mathrm{ZnSO}_{4}$ (pH 6.5). The hydroponic cultures were maintained in glass bottles and were kept $\left(\sim 28^{\circ} \mathrm{C}\right)$ in sterile environment in such a way to receive ample sun light. The cultures were aerated intermittently with an air bubbler. The nutrient solution was replaced by freshly prepared solution in every 1 week [10].

\subsection{Transfer of Infection to the Test Plants}

The pathogen, $R$. solanacearum isolate was injected into the lower part of the stem of all the test plants in both pot and hydroponics systems [10].

\subsection{Biochemical Analyses}

Total (\%) carbohydrate, starch, reducing sugar, protein, phenol and proline were estimated to evaluate the effect of $R s$ infection on both the test and control plants. The total carbohydrate in the sample was analyzed by Anthrone method at $630 \mathrm{~nm}$ [12]. The starch content in the sample was estimated using Anthrone reagent at $630 \mathrm{~nm}$, the glucose content in the sample was estimated first, which was multiplied by a factor of 0.9 to arrive at the starch content [12]. The total protein in the sample was analyzed by Lowry's method [13]. The phenol content in the sample was checked using Folin-Ciocalteau reagent [12]. The total proline content in the sample was estimated at $520 \mathrm{~nm}$ using acidic ninhydrin to form the chromophore (red color) [12].

\subsection{Isozyme Analyses}

To analyze the production of scavengers of the ROS such as SOD, POX and CAT, native polyacrylamide gel electrophoresis (PAGE) [14] was performed. For this, leaf samples from control and infected plants were frozen in liquid nitrogen, immediately after harvesting (Iwatani$\mathrm{NL}-50$, Japan) at $-196^{\circ} \mathrm{C}$. Then, samples were suspended in $0.05 \mathrm{M}$ Tris buffer (pH 7.2) and kept for $2 \mathrm{~h}$ at $4^{\circ} \mathrm{C}$. Crude extract was collected by filtration and the filtrate was centrifuged at $9400 \times \mathrm{g}, 4^{\circ} \mathrm{C}$ for $20 \mathrm{~min}$ and the supernatant was used for analyses. PAGE gel was prepared 
with $5 \%$ stacking gel and $10 \%$ separating gel, run at $4{ }^{\circ} \mathrm{C}$ for $3 \mathrm{~h}$ at $40 \mathrm{~mA}$. With the completion of the electrophoresis, the gel was carefully removed and soaked in suitable staining solutions.

\section{Detection of Isozymes}

Method of Ravindranath and Fridovich [10,15] was used for the detection of SOD isozymes. Benzidine staining method was used for POX isozymes [10,12]. Catalase isozymes was detected by Potassium ferricyanide method $[10,12]$.

\subsection{Relative Mobility Calculation}

Migration distance or relative mobility $(\mathrm{Rm})$ of the isozyme bands was calculated based on their relative migration on the gel. The images of gel were taken on a gel documentation system (Bio-Rad Gel Doc XR), and the images were processed using Total Lab Technology software (TL 100 Single dongle UK, by non-linear dynamics).

\subsection{Statistics}

All experiments were conducted in triplicates. Statistical Package for Social Sciences (SPSS) was used to prepare the graphs and significance level at 0.05 and 0.01 by Student's t-test. Two-tailed test of significance was done for all the samples. Adobe Photoshop CS5 was used to set the figures.

\section{Results}

The prime objective of this study was to examine the biochemical changes and expression profiles of the oxidative stress enzymes (OSE) due to the biotic stress induced by infecting the test plants with $R$. solanacearum $(R s)$. Three mangroves known for resistant to the attack of pathogens, i.e., A. officinalis, D. trifoliata, E. agallocha were used in this study. In the experimental design, all plants (in sufficient number) were grown in two sets, i.e., in pot and hydroponic systems (Figure 1).

\subsection{Biochemical Profiles}

In order to examine the biochemical behaviours due to $R s$ infection, six biochemical components of the three mangroves under examination were analyzed as subdivided below (Figures 2 (a)-(f)).

\subsubsection{Estimation of Total Carbohydrate}

Total carbohydrate content in plants grown in pots and as hydroponics (both $R s$ infected) showed variations against their respective controls (Figure 2(a)). Of three mangroves, A. officinalis showed $24 \%$ increase (pot), while

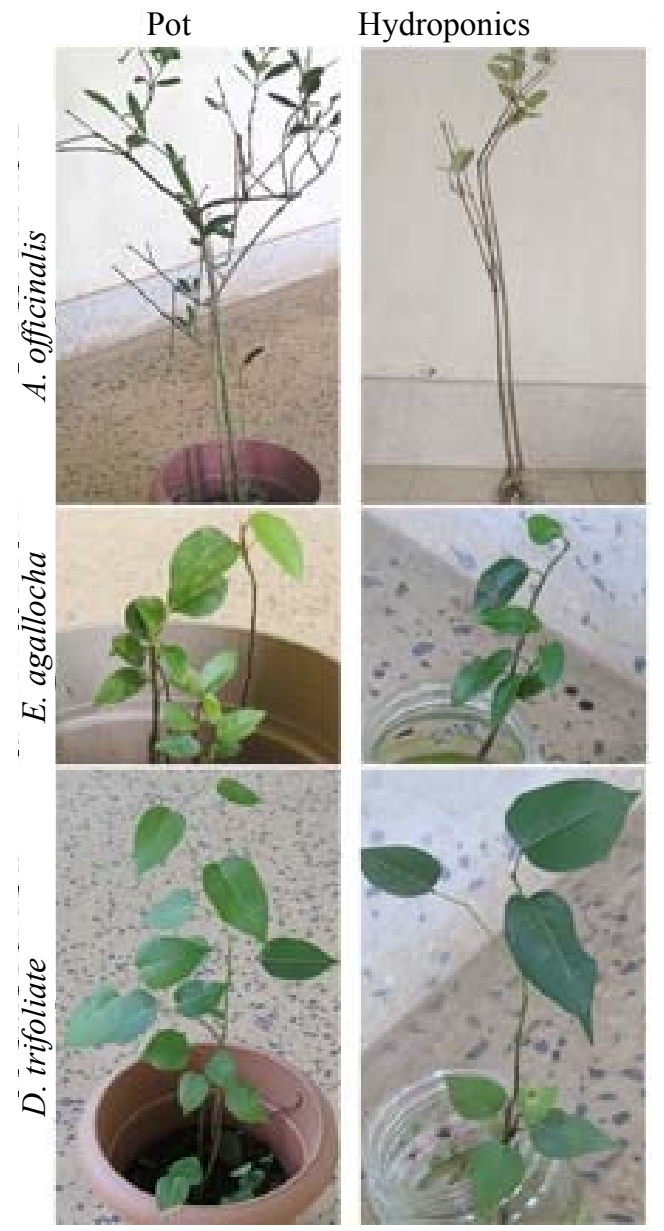

Figure 1. Experimental design of plants: Three mangroves (D. trifoliata, A. officinalis and E. agallocha) grown in pot and hydroponic systems in sufficient number with controls.

its hydroponics showed $15 \%$ increase; $D$. trifoliata grown in pot did not show a significant difference, while corresponding hydroponics showed $28 \%$ increase; and $E$. agallocha showed $34 \%$ increase (pot), while its hydroponics did not show significant difference. Results show that carbohydrate content in all infected plants grown in pots was high in the range of $24 \%-36 \%$, while corresponding infected hydroponic plants showed no significant difference.

\subsubsection{Estimation of Total Starch}

Total starch content in plants grown in pots and as hydroponics (both $R s$ infected) showed variations against their respective controls (Figure 2(b)). Of three mangroves, A. officinalis showed $15 \%$ increase (pot), while its hydroponics showed $26 \%$ increase; $D$. trifoliata grown in pot showed insignificant increase, while corresponding hydroponics showed 68\% increase; and E. agallocha showed $43 \%$ decrease (pot), while its hydroponics showed $65 \%$ increase. Thus infected hydoponic mangroves 


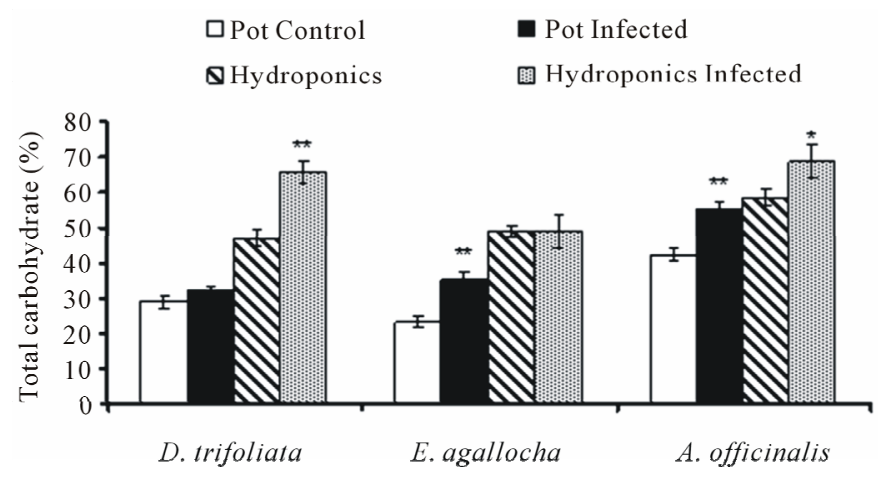

(a)

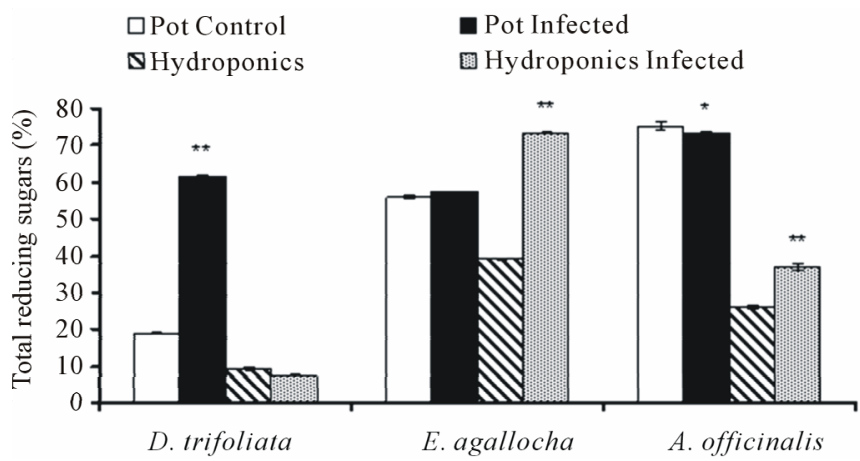

(c)

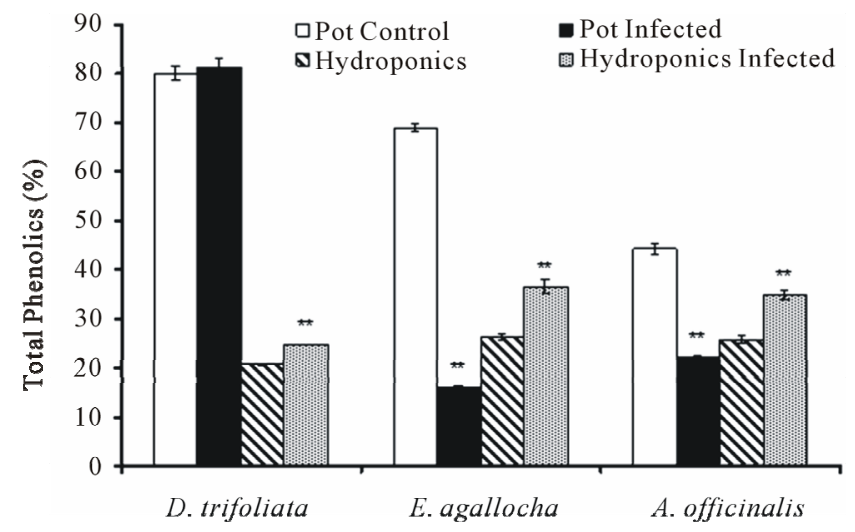

(e)

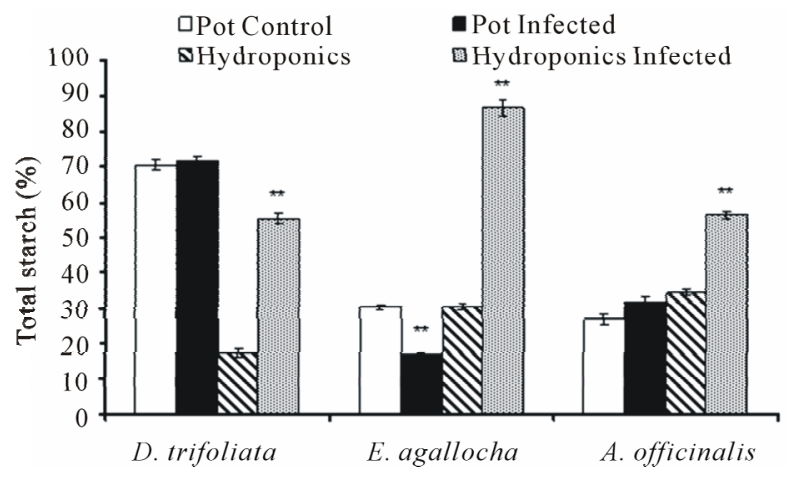

(b)

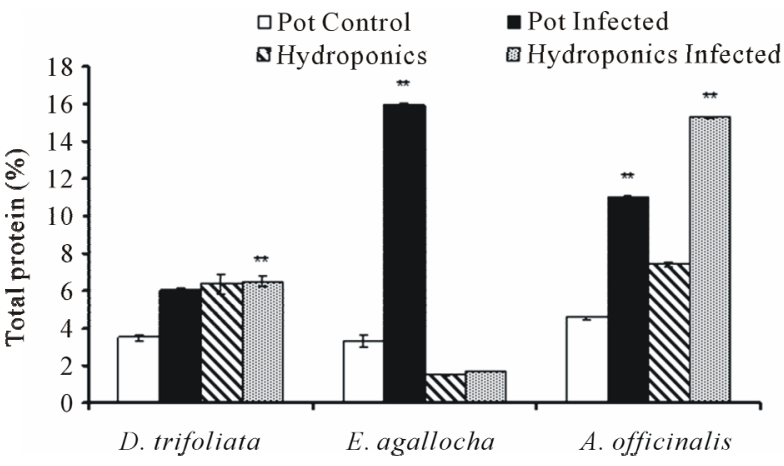

(d)

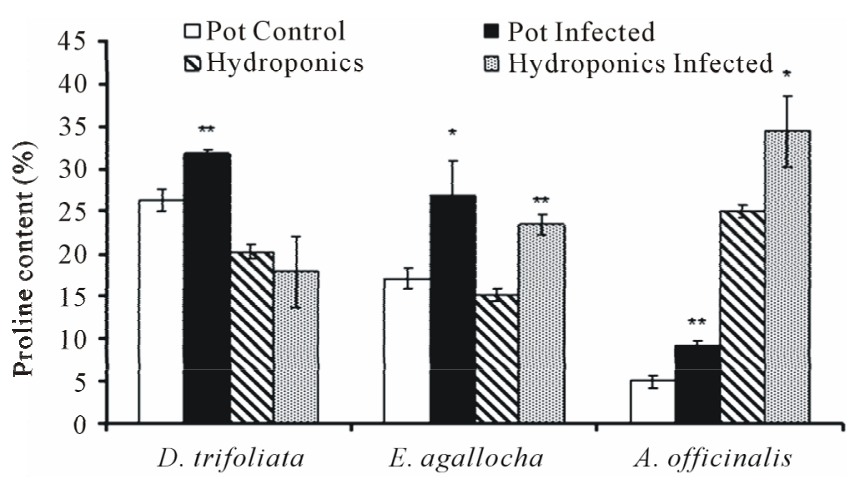

(f)

Figure 2. Biochemical characterization of plants: (a) Total carbohydrate, (b) total starch, (c) total reducing sugars, (d) total protein, (e) total phenolics, and (f) proline content. ${ }^{*}$ indicates significance at $\mathbf{p}<0.05$ and ${ }^{* *}$ indicates significance at $p<0.01$.

showed higher starch content than their controls.

\subsubsection{Estimation of Total Reducing Sugar}

Total reducing sugar in plants grown in pots and as hydroponics (both $R s$ infected) showed variations against their respective controls (Figure 2(c)). Of three mangroves, A. officinalis showed insignificant increase (pot), while its hydroponics showed $29 \%$ increase; $D$. trifoliata grown in pot showed $70 \%$ increase, while corresponding hydroponics showed insignificant difference; and $E$. agallocha in pot showed insignificant difference, while its hydroponics showed $46 \%$ increase.

\subsubsection{Estimation of Total Protein}

Total protein in plants grown in pots and as hydroponics (both $R s$ infected) showed variations against their respective controls (Figure 2(d)). Of three mangroves, A. officinalis in pot showed steep increase $(58 \%)$, its hydroponics also showed comparable (51\%) increase; $D$. trifoliata grown in pot showed $42 \%$ increase, while its corresponding hydroponics did not show significant increase; and E. agallocha in pot showed significantly high increase (79\%), while its hydroponics showed insignificant increase. Interestingly, almost all mangroves showed increased protein content upon infection with $R s$ isolate. 


\subsubsection{Total Phenolic Content}

Total phenolics in plants grown in pots and as hydroponics (both $R s$ infected) showed variations against their respective controls (Figure 2(e)). Of three mangroves, $A$. officinalis in pot showed $51 \%$ decrease, while its hydroponics showed $26 \%$ increase; $D$. trifoliata grown in pot did not show significant increase, while its corresponding hydroponics showed $16 \%$ increase; and E. agallocha in pot showed $74 \%$ decrease, while its hydroponics showed $28 \%$ increase. The results show that infected plants (both in pot and hydroponic systems) did not show a consistent pattern of phenolic contents, which showed a swing of decrease or increase between pot and hydroponic systems.

\subsubsection{Proline Content}

The proline content in plants grown in pots and as hydroponics (both $R s$ infected) showed variations against their respective controls (Figure 2(f)). Of three mangroves, A. officinalis in pot showed $45 \%$ increase, while its hydroponics showed $27 \%$ increase; $D$. trifoliata grown in pot showed $17 \%$ increase, while its corresponding hydroponics showed no significant difference; and E. agallocha in pot showed $36 \%$ increase, while its hydroponics showed 35\% increase. All infected plants in general showed elevated proline content.

\subsection{Isozyme Analysis}

Three representative enzymes of oxidative stress, viz., POX, SOD and CAT were analyzed based on their physical appearance on the PAGE upon specific staining and relative $R m$ values (Figures $\mathbf{3}$ and $\mathbf{4}$, Tables $\mathbf{1}$ and $\mathbf{2}$ ).

\subsubsection{SOD Characterization}

SOD isozyme profile also showed variations (Figure 3 and Table 1). Infected A. officinalis in pot and hydroponics showed four isoforms each and their controls showed only three isozymes each, common isoforms of plants in pots and hydroponics were with an $R m$ of 0.78 and 0.75 , respectively. The control and infected $D$. trifoliata in pot showed two and five isoforms, respectively; while its control and infected hydoponic showed three and four isoforms, respectively with $R m 0.72$ in common. E. agallocha controls in pot showed three isoforms and its infected counterpart showed five isoforms; while both control and infected hydoponic showed three isoforms each. In general, number of SOD isozymes in infected mangroves showed 1 or 2 more isozymes with comparable $R m$ values than their respective controls.

\subsubsection{POX Characterization}

POX isozyme profile also showed variations (Figure 4

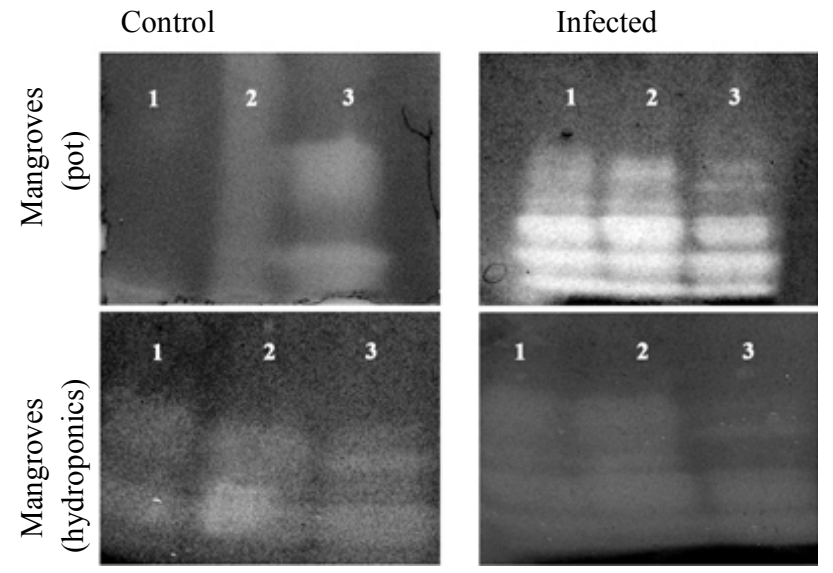

Figure 3. Isozyme profiles of SOD of five plants in pot and hydroponic systems with respective controls. In the upper panel numbers $1,2,3$ are given for three mangroves $(E$. agallocha, $A$. officinalis and $D$. trifoliata, respectively) grown in pot (upper row) and hydroponics (lower row). Isozyme bands for control and infected samples are marked.

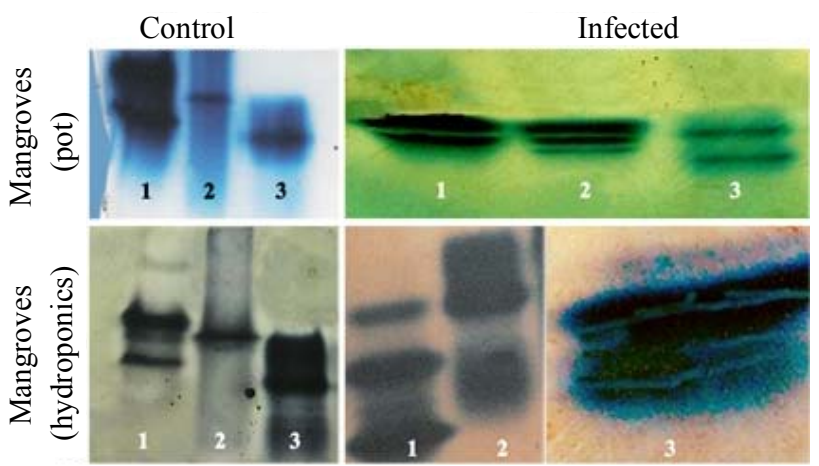

Figure 4. Isozyme profiles of POX of five plants in pot and hydroponic systems with respective controls. Profiles of three mangroves, E. agallocha, A. officinalis and D. trifoliata in lane 1, 2 and 3, respectively. Left panel is the profiles of these three plants cultivated in pots, and right panel is of those cultivated as hydroponics. Each row is for plants grown either in pot or as hydroponics.

and Table 2). Control A. officinalis in pot showed one isoform and respective infected showed two isoforms, while its control hydroponics showed two isoforms and corresponding infected plants showed there isoforms with $R m 0.43$ in common. Both control and infected $D$. trifoliata in pot showed two isoforms each, while both its control and infected hydroponics showed four isoforms each. Both control and infected E. agallocha in pot showed three isoforms each with one $R m(0.49)$ in almost common; while both its control and infected hydoponics showed five isoforms with one common $\mathrm{Rm}(0.80)$. The results show that plants gown under hydroponic system expressed 1 or 2 more POX isozymes than their respective controls. 
Table 1. Superoxide dismutase: comparison of relative mobility values of all plants grown in pot and hydroponic systems. "a" indicates similarity of relative mobility between corresponding control and infected plants and " $b$ " indicates similarity of relative mobility between infected plants in pot and hydroponic systems.

\begin{tabular}{|c|c|c|c|c|}
\hline \multirow{2}{*}{ Plant name } & \multicolumn{2}{|c|}{ Grown in pot } & \multicolumn{2}{|c|}{ Grown in hydroponics } \\
\hline & Normal & Treated & Normal & Treated \\
\hline A. officinalis & $\begin{array}{c}0.20 \\
0.48 \\
\mathbf{0 . 7 8}^{\mathbf{a}}\end{array}$ & $\begin{array}{l}\mathbf{0 . 4 6} \\
\mathbf{0 . 6 2}^{\mathbf{b}} \\
\mathbf{0 . 7 8}^{\mathbf{b}} \\
0.88^{\mathrm{b}}\end{array}$ & $\begin{array}{c}0.46 \\
0.59 \\
\mathbf{0 . 7 4}^{\mathbf{a}}\end{array}$ & $\begin{array}{l}\mathbf{0 . 4 6}^{\text {b }} \\
\mathbf{0 . 6 1}^{\text {b }} \\
\mathbf{0 . 7 5}^{\text {a }} \\
0.88^{\text {b }}\end{array}$ \\
\hline E. agallocha & $\begin{array}{l}0.31 \\
0.49 \\
0.69\end{array}$ & $\begin{array}{l}0.39 \\
0.52 \\
0.64 \\
0.78 \\
0.87\end{array}$ & $\begin{array}{l}0.58 \\
0.85 \\
0.95\end{array}$ & $\begin{array}{l}0.47 \\
0.72 \\
0.88\end{array}$ \\
\hline D. trifoliata & $\begin{array}{c}\mathbf{0 . 6 0}^{\mathbf{a}} \\
0.67\end{array}$ & $\begin{array}{c}0.38 \\
0.53 \\
\mathbf{0 . 6 1}^{\mathbf{a}} \\
0.74 \\
0.86\end{array}$ & $\begin{array}{c}0.53 \\
\mathbf{0 . 7 2}^{\mathrm{a}} \\
0.85\end{array}$ & $\begin{array}{c}0.41 \\
0.59 \\
\mathbf{0 . 7 2}^{\mathbf{a}} \\
0.89\end{array}$ \\
\hline
\end{tabular}

Table 2. Peroxidase: comparison of relative mobility values of all plants grown in pot and hydroponic systems. "a” indicates similarity of relative mobility between corresponding control and infected plants.

\begin{tabular}{ccccc}
\hline \multirow{2}{*}{ Plant name } & \multicolumn{2}{c}{ In pot } & \multicolumn{2}{c}{ Hydroponics } \\
\cline { 2 - 5 } & Control & Infected & Normal & Infected \\
\hline \multirow{3}{*}{ A. officinalis } & 0.41 & 0.26 & $\mathbf{0 . 4 3}^{\mathbf{a}}$ & 0.15 \\
& & 0.35 & 0.48 & 0.28 \\
& & & & $\mathbf{0 . 4 3}^{\mathbf{a}}$ \\
E. agallocha & 0.31 & 0.27 & 0.56 & 0.60 \\
& $\mathbf{0 . 4 9}^{\mathbf{a}}$ & 0.36 & 0.65 & 0.71 \\
& 0.69 & $\mathbf{0 . 5 0}^{\mathbf{a}}$ & $\mathbf{0 . 8 0}^{\mathbf{a}}$ & $\mathbf{0 . 8 0}^{\mathbf{a}}$ \\
& & & 0.85 & 0.90 \\
D. trifoliata & 0.60 & 0.31 & 0.13 & 0.65 \\
& 0.67 & 0.45 & 0.43 & 0.71 \\
& & & 0.55 & 0.77 \\
\hline
\end{tabular}

\subsubsection{CAT Characterization}

We could not visualize any catalase isoforms on gel, but the addition of $\mathrm{H}_{2} \mathrm{O}_{2}$ to the staining solution resulted in the liberation of gas bubbles, which indicated the presence of CAT in the sample.

\section{Discussion}

In this study, we isolated and characterized $R$. solanacearum $(R s)$ from severely wilted ginger [10], and used it to induce biotic stress in three selected plants of mangroves, which were analysed for biochemical changes coupled with the isoenzymes profiles of OSE. These test plants were grown under two conditions; viz., normal (in pots) and controlled (hydroponics) systems to judge maximum possible differences upon induction of biotic stress. Rs induced biotic stress did not cause any wilt symptom in mangroves, but normal biochemical and OSE isozyme patterns of all plants, especially those grown as hydroponics were elicited to significantly higher levels.

Morphological evidences of $R s$ induced bacterial wilt on plants include rolling of the leaf margins, sectorial yellowing and necrosis followed by complete degradation of plant material [16]. Biochemical, genetic and molecular approaches show that this bacterium possesses a wide array of virulence factors like mechanical plugging of xylem vessels; toxic action of exopolysaccharide secreted by the pathogen and enzymatic attack on plant tissue $[17,18]$. Plants produce numerous ROS during stress [19] and antioxidative scavengers like POX, SOD, and CAT. Of this SOD, the first enzyme in the enzymatic antioxidative pathway, is a crucial rate limiting enzyme, as we described earlier in Ficus religiosa [7]. The antioxidant enzymes or OSE protect halophytes (e.g., mangroves) from deleterious ROS production during salt stress, and the genetic information from mangroves and other halophytes would be helpful in defining the roles of individual isoforms produced by the oxidative stress enzymes [19].

We for the first time studied the effect of biochemical and molecular changes in mangroves. Our results clearly show that mangroves did not show any wilt symptoms. However, the biotic stress could alter the biochemical and OSE profiles. Mangroves have developed many defence mechanisms against pathogenic stress. The factors which affect the immune response of mangroves to pathogens include: inoculum dosage, degree of virulence of pathogen, resistance of host, environmental conditions under which the interaction proceeds, time interval between immunization and challenge inoculation [20]. Mangroves develop a hypersensitive response (HR) in which necrotic lesions are formed at the site of pathogen entry. Just before or concomitant with the appearance of an HR is the increased synthesis of several members of pathogenic-related proteins in the inoculated plants [20]. The mangroves generating pathogenic-related proteins exhibit anti-microbial activity either in vitro or in vivo [21]. A variety of signaling molecules like ethylene and jasmonic acid are responsible for the local and systematic disease resistance, which may activate various defence responses, and thus resistance to certain pathogens.

A few or no study is seen in literature, which relate the biochemical changes and expression patters of the isoenzymes of OSE, i.e., SOD, POX, CAT, etc. as markers in response to induced biotic stress, especially in mangroves. However, many studies demonstrate such changes pertaining to a multitude of abiotic stressors. Zhang et al. [22] studied the effects of multiple heavy metal stress 
on the activity of antioxidative enzymes and lipid peroxidation in leaves and roots of $K$. candel and B. gymnorrhiza, which showed that the dynamic tendency of SOD, POX and CAT activities in roots of heavy metalstressed plants all ascended, and then declined, and that the increase in enzyme activities demonstrated that $K$. candel is more tolerant to heavy metals than B. gymnorrhiza. Salt induced biochemical changes were studied in hydroponically grown plants of a salt secrector mangrove, Aegiceras corniculatum [23] and showed that leaf protein content decreased slightly and SDS-PAGE analysis showed nearly identical protein profiles in control and salt treated samples, proline content decreased by $75 \%$ in the leaves with the accumulation of polyphenols.

Plants have evolved a wide range of mechanisms to cope with biotic and abiotic stresses. To date, the molecular mechanisms that are involved in each stress has been revealed comparatively independently, and so our understanding of convergence points between biotic and abiotic stress signaling pathways remain rudimentary [23]. Emerging evidences suggest that hormone signaling pathways regulated by abscisic acid, salicylic acid, jasmonic acid and ethylene, as well as ROS signaling pathways, play key roles in the crosstalk between biotic and abiotic stress signalling [24]. Protective metabolic adaptations alter physiological reactions of the whole plant. Paramount among the mechanisms are oxygen radical scavenging, maintenance of ion uptake and water balance, and reactions altering carbon and nitrogen allocation, such that reducing power is defused [6]. Metabolomics could contribute significantly to the study of stress boilogy in plants and other organisms by identifying different compounds, such as by-products of stress metabolism, stress signal transduction molecules or molecules that are part of the acclimation response of plants [4]. These could be further tested by direct measurements, correlated with changes in transcriptome and proteome expression and confirmed by mutant analysis.

\section{Conclusion}

Our study demonstrated the effect of biotic stress in the biochemical as well as the OSE isozyme profiles of mangroves. The biochemical profile of plants cultivated in pot and hydroponics systems greatly changed upon biotic stress induction. The plants kept in hydroponic system, which did not face any nutrient and water stress produced more proteins, phenolics and proline than plants grown in pot system. Hence, they tried to resist the biotic stress by modifying their metabolic pathways. Further studies at molecular level are necessary to get a real picture of the impact of biotic stress on plant metabolism. Thus, the employment of resistant cultivars is a good strategy for low cost and efficient control of bacterial wilt in crops.

\section{Acknowledgements}

The research Grant No. 83/2007/ KSCSTE from the Kerala State Council for Science, Technology and Environment, Government of Kerala is gratefully acknowledged. The authors also declare that there exists no conflict of interest.

\section{REFERENCES}

[1] M. Fegan and P. Prior, "Recent Developments in the Phylogeny and Classification of Ralstonia solanacearum," The 1st International Tomato Symposium, Orlando, 2004.

[2] T. P. Denny, "Plant Pathogenic Ralstonia Species," In: S. S. Gnanamanickam, Ed., Plant Associated Bacteria, part III, Springer, Berlin, 2006, pp. 573-644. http://dx.doi.org/10.1007/978-1-4020-4538-7 16

[3] E. B. French, L. Gutarra, P. Alev and J. Elphinstone, "Culture Media for Ralstonia solanacearum Isolation, Identification and Maintenance," Phytopathology, Vol. 30, No. 3, 1995, pp.126-130.

[4] V. Shulaev, D. Cortes, G. Miller and R. Mittler, "Metabolomics for Plant Stress Response," Physiologia Plantarum, Vol. 132, No. 2, 2008, pp. 199-208. http://dx.doi.org/10.1111/j.1399-3054.2007.01025.x

[5] H. K. Lichtenthaler, "The Stress Concept in Plants: An Introduction," Annals of the New York Academy of Sciences, Vol. 851, No. 1, 1998, pp. 187-198. http://dx.doi.org/10.1111/j.1749-6632.1998.tb08993.x

[6] H. J. Bohnert and E. Sheveleva, "Plant Stress Adaptations -Making Metabolism Move," Current Opinion in Plant Biology, Vol. 1, No. 3, 1998, pp. 267-274. http://dx.doi.org/10.1016/S1369-5266(98)80115-5

[7] R. B. Smitha, T. Bennans, C. Mohankumar and S. Benjamin, "Oxidative Stress Enzymes in Ficus religiosa L.: Biochemical, Histochemical and Anatomical Evidences," Journal of Photochemistry and Photobiology, Vol. 95, No. 1, 2009, pp. 17-25. http://dx.doi.org/10.1016/j.jphotobiol.2008.12.004

[8] K. P. Asish, B. D. Anath and M. Prasanna, "Defense Potentials to $\mathrm{NaCl}$ in a Mangrove, Bruguiera parviflora: Differential Changes of Isoforms of some Antioxidative Enzymes," Journal of Plant Physiology, Vol. 161, No. 1, 2004, pp. 531-542.

[9] A. L. Carlos and S. B. Leonardo, "Biovar-Specific and Broad-Spectrum Sources of Resistance to Bacterial Wilt (Ralstonia solanacearum) in Capsicum," Crop Breeding and Applied Biotechnology, Vol. 4, No. 1, 2004, pp. 350355.

[10] S. Sreedevi, K. N. Remani and S. Benjamin, "Biotic Stress Induced Biochemical and Isozyme Variations in Ginger and Tomato by Ralstonia solanacearum," American Journal of Plant Sciences, Vol. 4, No. 8, 2013, pp. 1601-1610.

[11] J. W. Shive and W. R. Robbins, "Methods of Growing Plants in Solution and Sand Cultures," New Jersey Agri- 
cultural Experiment Station, Vol. 636, No. 1, 1937.

[12] S. Sadasivam and A. Manickam, "Biochemical Methods for Agricultural Sciences," Wiley Eastern Ltd., New Delhi, 1992.

[13] O. H. Lowry, N. J. Rosebrough, A. L. Farr and R. J. Randall, "Protein Measurement with the Folin Phenol Reagent," Journal of Biological Chemistry, Vol. 193, No. 1, 1951, pp. 265-275.

[14] U. K. Laemmli, "Cleavage of Structural Protein during the Assembly of the Head of Bacteriophage T4," Nature, Vol. 227, No. 2, 1970, pp. 680-685. http://dx.doi.org/10.1038/227680a0

[15] S. D. Ravindranath and I. Fridovich, "Isolation and Characterization of Manganese Containing SOD from Yeast," Journal of Biochemistry, Vol. 250, No. 15, 1975, pp. 6107-6112.

[16] J. G. Elphinstone, "The Current Bacterial Wilt Situation: A Global Overview. Bacterial Wilt Disease and the Ralstonia solanacearum Species Complex," American Phytopathological Society (APS Press), St. Paul, 2005.

[17] H. Jahr, J. Dreier, D. Meletzus, R. Bahro and R. Eichenlaub, "The Endo- $\beta$-1, 4-glucanase CelA of Clavibacter michiganensis subsp. michiganensis Is a Pathogenicity Determinant Required for Induction of Bacterial Wilt of Tomato," Molecular Plant and Microbe Interraction, Vol. 13, No. 7, 2000, pp. 703-714. http://dx.doi.org/10.1094/MPMI.2000.13.7.703

[18] P. K. Sambasivam and D. Girija, "Biochemical Characterization of Ralstonia solanacearum Infecting Ginger," Annals of Plant Protection Sciences, Vol. 14, No. 2, 2006, pp. 419-423.

[19] M. N. Jithesh, S. R. Prashanth, K. R. Sivaprakash and A. K. Parida, "Antioxidative Response Mechanisms in Halophytes: Their Role in Stress Defence," Journal of Genetics, Vol. 85, No. 3, 2006, pp. 237-254. http://dx.doi.org/10.1007/BF02935340

[20] L. C. Van Loon, "Pathogenesis-Related Proteins," Plant Molecular Biology, Vol. 4, No. 2, 1985, pp. 111-116. http://dx.doi.org/10.1007/BF02418757

[21] S. K. Datta and S. Muthukrishnan, "Pathogenesis-Related Proteins in Plants, CRC Press, Washington DC, 1999. http://dx.doi.org/10.1201/9781420049299

[22] F. Q. Zhang, Y. S. Wang, Z. P. Lou and J. D. Dong, "Effect of Heavy Metal Stress on Antioxidative Enzymes and Lipid Peroxidation in Leaves and Roots of Two Mangrove Plant Seedlings (Kandelia candel and Bruguiera gymnorrhiza)," Chemosphere, Vol. 67, No. 1, 2007, pp. 44-50. http://dx.doi.org/10.1016/j.chemosphere.2006.10.007

[23] A. K. Parida, A. B. Das, Y. Sanada and P. Mohanty, "Effects of Salinity on Biochemical Components of the Mangrove, Aegiceras corniculatum," Aquatic Botany, Vol. 80, No. 2, 2004, pp. 77-87.

http://dx.doi.org/10.1016/j.aquabot.2004.07.005

[24] M. Fujita, Y. Fujita, Y. Noutoshi, F. Takahashi, Y. Narusaka and K. Yamaguchi-Shinozaki, "Crosstalk between Abiotic and Biotic Stress Responses: A Current View from the Points of Convergence in the Stress Signaling Networks," Current Opinion in Plant Biology, Vol. 9, No. 4, 2006, pp. 436-442. 